\title{
Aspectos ambientais do acordo entre União Europeia e Mercosul
}

\author{
Environmental aspects of the agreement between the European Union and Mercosur \\ Aspectos ambientales del acuerdo entre la Unión Europea y Mercosur
}

Recebido: 09/11/2021 | Revisado: 18/11/2021 | Aceito: 21/11/2021 | Publicado: 02/12/2021

\author{
Rhadson Rezende Monteiro \\ ORCID: https://orcid.org/0000-0001-7992-6110 \\ Universidade Estadual de Santa Cruz, Brasil \\ Universidade Federal do Recôncavo da Bahia, Brasil \\ E-mail: rhrmonteiro@uesc.br \\ Christiana Cabicieri Profice \\ ORCID: https://orcid.org/0000-0002-1972-9622 \\ Universidade Estadual de Santa Cruz, Brasil \\ E-mail: ccprofice@uesc.br \\ Fernando Enrique Grenno \\ ORCID: https://orcid.org/0000-0002-7082-1328 \\ Universidade Estadual de Santa Cruz, Brasil \\ E-mail: fgrenno@gmail.com \\ Alexandre Schiavetti \\ ORCID: https://orcid.org/0000-0001-8429-7646 \\ Universidade Estadual de Santa Cruz, Brasil \\ Investigador Asociado CESIMA/CENPAT, Argentina \\ E-mail: aleschi@uesc.br
}

\begin{abstract}
Resumo
Após 20 anos de negociações diplomáticas, foi firmado as bases para o acordo de integração econômica entre o Mercado Comum do Sul (Mercosul) e a União Europeia (UE). Em 28 de junho de 2019, concluíram-se, em Bruxelas, as tratativas de um Acordo de Associação que prevê a implantação de uma zona de livre comércio compreendendo os dois blocos. Dentre os 17 capítulos do acordo de livre-comércio há o capítulo "Comércio e Desenvolvimento Sustentável" no qual é pré acordado que os países integrantes dos dois blocos devem reiterar compromissos multilaterais firmados, como os da Convenção-Quadro das Nações Unidas sobre a Mudança do Clima e o Acordo de Paris. Além disso, seriam somados outros esforços relacionados à conservação e ao uso sustentável da biodiversidade, respeito aos direitos trabalhistas e proteção dos direitos das populações indígenas. O presente artigo tem como objetivo apresentar as políticas ambientais prevista nesse acordo. Como método de pesquisa foi utilizado levantamento bibliográfico em sites de pesquisa acadêmica, além de reportagens em jornais de grande circulação. Primeiro se fará um breve histórico da negociação frente às políticas ambientais. Após é realizada uma análise jurídico normativa do texto do acordo, especificamente no que tange ao capítulo de desenvolvimento sustentável, em livre tradução do texto original. Por fim uma breve conclusão sobre os entraves para efetividade desse acordo frente às políticas ambientais que vêm sendo empregadas pelo Ministério do Meio Ambiente, do Governo Federal desde 2020, após a publicação da minuta.
\end{abstract}

Palavras-chave: Meio ambiente; Direito; Mercosul; União Europeia.

\begin{abstract}
After 20 years of diplomatic derivation, it was signed as the basis for the economic integration agreement between the Common Market of the South (Mercosur) and the European Union (EU). On June 28, 2019, negotiations were concluded in Brussels on an Association Agreement that provides for the establishment of a free trade zone comprising the two blocs. Among the 17 chapters of the free trade agreement, there is the chapter "Trade and Sustainable Development" in which it is pre-agreed that the member countries of the two blocs must reiterate multilateral commitments signed, such as those of the United Nations Framework Convention on the Change of Climate and the Paris Agreement. In addition, other efforts related to the conservation and sustainable use of biodiversity, respect for labor rights and protection of the rights of indigenous populations would be added. This article aims to present the environmental policies provided for in this agreement. As a research method, a bibliographic survey on academic research sites was used, in addition to reports in large-circulation newspapers. First, a brief history of the negotiation regarding environmental policies will be made. Once removed, a normative legal analysis of the text of the agreement is carried out, specifically with regard to the chapter on sustainable development, in free translation of the original text. Finally, a brief conclusion about the obstacles to the effectiveness of this agreement to the environmental policies it causes, used by the Ministry of the Environment, of the Federal Government since 2020, after the publication of the draft.
\end{abstract}

Keywords: Environment; Right; Mercosur; European Union. 


\begin{abstract}
Resumen
Tras 20 años de derivación diplomática, se firmó como base del acuerdo de integración económica entre el Mercado Común del Sur (Mercosur) y la Unión Europea (UE). El 28 de junio de 2019 concluyeron en Bruselas las negociaciones sobre un Acuerdo de Asociación que prevé el establecimiento de una zona de libre comercio que comprenda los dos bloques. Entre los 17 capítulos del tratado de libre comercio, se encuentra el capítulo "Comercio y Desarrollo Sostenible" en el que se acordó previamente que los países miembros de los dos bloques deben reiterar compromisos multilaterales suscritos, como los de la Convención Marco de Naciones Unidas. sobre el Cambio Climático y el Acuerdo de París. Además, se sumarían otros esfuerzos relacionados con la conservación y uso sostenible de la biodiversidad, el respeto a los derechos laborales y la protección de los derechos de las poblaciones indígenas. Este artículo tiene como objetivo presentar las políticas ambientales previstas en este acuerdo. Como método de investigación se utilizó una encuesta bibliográfica en sitios de investigación académica, además de reportajes en periódicos de gran circulación. Primero, se hará una breve historia de la negociación en materia de políticas ambientales. Posteriormente, se realiza un análisis jurídico normativo del texto del convenio, específicamente sin hacer referencia al capítulo sobre desarrollo sostenible, en traducción libre del texto original. Finalmente, una breve conclusión sobre los obstáculos a la efectividad de este convenio a las políticas ambientales que afectan a las empleadas por el Ministerio del Ambiente, del Gobierno Federal desde 2020 , luego de la publicación del plazo.
\end{abstract}

Palabras clave: Medio ambiente; Derecho; Mercosur; Unión Europea.

\title{
1. Introdução
}

O Acordo entre Mercosul e UE é um importante instrumento para o avanço da integração intercontinental e para o desenvolvimento econômico, mais também para avanços sociais, trabalhista e principalmente de preservação do Meio Ambiente ao consideraras três dimensões da sustentabilidade de forma integrada, quer seja, a econômica, social e ambiental em seu corpo de lei. De acordo com a BBC (2019), o acordo comercial envolve $25 \%$ da economia global e 780 milhões de pessoas - quase $10 \%$ da população do mundo.

A UE é o segundo parceiro comercial do Mercosul e o primeiro em matéria de investimentos. O Mercosul é o oitavo principal parceiro comercial extrarregional da UE. A corrente de comércio bi regional foi de mais de US\$ 90 bilhões em 2018. Em 2017, o estoque de investimentos da UE no bloco sul-americano somava cerca de US\$ 433 bilhões. O Brasil registrou, em 2018, um comércio de US\$ 76 bilhões com a UE e superávit de US\$ 7 bilhões. O Brasil exportou mais de US\$ 42 bilhões, aproximadamente $18 \%$ do total exportado pelo país. O Brasil destaca-se como o maior destino do investimento externo direto (IED) dos países da UE na América Latina, com quase metade do estoque de investimentos na região. O Brasil é o quarto maior destino de IED da UE, que se distribui em setores de alto valor estratégico. Conforme estimado pelo Ministério da Economia o Acordo representará um incremento do PIB brasileiro na ordem de US\$ 87,5 bilhões em 15 anos, podendo chegar a US\$ 125 bilhões se consideradas a redução das barreiras não tarifárias e o incremento esperado na produtividade total dos fatores de produção. (Machado \& Lupi, 2020).

Outrossim, o acordo entre os blocos econômicos reforça uma tendencia global, condicionando obrigatoriedade ao cumprimento de diversas metas de tratados internacionais do quais o Brasil já é signatária, tais como a Agenda 30 com os Objetivos do Desenvolvimento Sustentável e o Acordo de Paris, em especial, o que tange a questões de proteção ao meio ambiente e a biodiversidade.

De acordo com o Acordo de Paris, o Brasil deverá reduzir, até 2025, a emissão de gás com efeito estufa em $37 \%$, comparado aos índices de 2005, reflorestar 12 milhões de hectares da floresta Amazônica até 2030 e a UE deverá reduzir as emissões domésticas em 40\% até 2030 (Rei et al, 2017).

Não obstante, o que se verifica nas práticas e que, a atuação do Ministério do Meio Ambiente do Brasil, entre 2019 e 2021 é diametralmente oposta as bases propostas pelo acordo.

Desde a publicação da minuta do tratado em 2019, o Brasil tem vivenciados sucessivos desmontes de sua política de proteção ambiental, tais como o esvaziamento de órgão de governança como o Conselho Nacional de Meio Ambiente e a redução da atuação de órgão de fiscalização como o IBAMA (Instituto Brasileiro de Meio Ambiente). Segundo o MapBiomas (2021) o 
Brasil perdeu 24 árvores por segundo em 2020 sendo que, 99,8\% dos desmates têm indício de ilegalidade e só 2\% tiveram alguma providência do Ibama.

Ainda segundo levantamento realizado pelo Inesc - Instituto de Estudos Socioeconômicos (2020) que monitorou e analisou 524 medidas normativas publicadas pelo Ministério do Meio Ambiente (MMA) e suas entidades Ibama, ICMBio, JBRJ em 2019 e 2020 a análise das medidas publicadas no Diário Oficial da União (DOU) revela que estaria em curso no Brasil o desmonte da capacidade institucional dos órgãos reguladores e fiscalizados da legislação ambiental. Segundo o mesmo estudo:

\begin{abstract}
"A pesquisa 'Dando nome aos bois: análise das medidas infralegais para o meio ambiente nos primeiros dois anos do governo Bolsonaro' teve um caráter qualitativo e foi realizada com apoio de especialistas de política e gestão ambiental. Cada uma das medidas estão categorizadas em grau de risco (1 a 5) no que tange ao seu impacto na redução do nível de proteção ambiental. Das 524 medidas, 317 representaram algum grau de risco. Destas, 48 foram consideradas de alto risco (sendo 38 de risco alto e 10 de risco muito alto). $\mathrm{O}$ estudo detalha ainda as 12 medidas mais danosas ao meio ambiente nos dois primeiros anos do governo Bolsonaro. (Inesc, 2020 p.2)"
\end{abstract}

Outrossim, a conjuntura política atual aponta para um processo de negação das bases do acordo o que pode prejudicar as pretensões do Brasil e, por conseguinte do demais países do Mercosul na aprovação do texto base.

O acordo também prevê integração com outras dimensões dos direitos sociais, tais como a proteção dos direitos dos trabalhadores, com a proibição de trabalhos forçados ou infantil, a não discriminação no ambiente de trabalho, a liberdade de associação e o direito de negociação coletiva, bem como a proteção dos direitos humanos e das comunidades indígenas sendo essas algumas das condições impostas pelo Acordo de Associação Mercosul-UE aos países envolvidos (Moura, 2019).

Para realizar essa análise, o artigo se divide da seguinte forma, o primeiro capítulo refere-se à uma breve síntese da conjuntura histórica, no segundo capítulo é feita a análise hermenêutica da minuta do tratado comercial, no que se refere ao título, "Comercio e Desenvolvimento Sustentável". Por fim é apresentado uma sucinta conclusão com apontamentos sobre o os rumos para a ratificação da minuta.

\title{
2. Histórico de Negociações e Tratados Ambientais
}

Na Conferência do Rio de Janeiro de 1992 sobre o Meio Ambiente e Desenvolvimento (Eco-92), o princípio 4, estabeleceu que: "para alcançar o desenvolvimento sustentável, a proteção ambiental deve constituir parte integrante do processo de desenvolvimento, e não pode ser considerada isoladamente deste" (BRASIL, 1992), a grosso modo, isso quer dizer que, para que um país cresça economicamente, a proteção do meio ambiente é essencial para que o desenvolvimento seja sustentável. Desde então, a observância do princípio do desenvolvimento sustentável tornou-se, pré-requisito a ser cumprido pelos países e empresas que desejam expandir e fortalecer suas relações comerciais a nível internacional.

Os primórdios dos processos de negociação que levaram a minuta de acordo de integração econômica em UE e Mercosul remota ao ano de 1999 após a vigência do Acordo-Quadro, que lançou bases para estabelecer uma zona de livre comércio, abrangendo as duas regiões, "os objetivos do Acordo-Quadro seriam (i) a preparação da liberalização das trocas comerciais entre os dois blocos; (ii) o apoio à integração do Mercosul, com a UE cooperando com apoio técnico que auxiliasse o Mercosul a gerir o seu próprio processo de integração “ (Thorstensen \& Nogueira, 2020)

Segundo, Thorstensen e Nogueira (2020) após a entrada em vigor do Acordo-Quadro, os blocos seguiram demonstrando compromisso com a integração inter-regional. Logo na primeira cúpula de Chefes de Estado da UE e do Mercosul, ocorrida no Rio de Janeiro em 28 de junho de 1999, decidiu-se por iniciar negociações por um Acordo de Associação, alicerçado nos pilares: diálogo político; cooperação; e comércio.

De acordo Pereira (2020) no decorrer da primeira década dos anos 2000 e até por volta de 2013, os ganhos com o boom das commodities assentou a agenda de ganhos de acesso a mercados nos bastidores para os países do Mercosul, após 2012, 
políticas protecionistas locais, impostos de exportações, licenciamentos de importações, entre outras, passaram a ser utilizadas pelas duas maiores economias do Mercosul Brasil e Argentina, o que dificultava negociações para uma área de livre-comércio, enquanto isso na União Europeia, a atenção ainda estava voltada para os efeitos da crise de 2008 (Pereira, 2020).

Com os avanços dos acordos ambientais internacionais, em especial a partir de 2015 com o estabelecimento da Agenda 30, dos Objetivos do Desenvolvimento Sustentável e do Acordo de Paris para a redução de Emissão de Gases Estufas, a pauta ambiental ganhar ainda maior relevância na integração para acordos comerciais.

Nesse sentido, o acordo firmado em 2019 entre União Europeia e o MERCOSUL confirma uma tendência de incluir premissa de que o progresso comercial não deve ocorrer à custa do meio ambiente (Romeiro, 2012). O que se verifica é que, os acordos comerciais recentes da União Europeia incluem um capítulo sobre desenvolvimento sustentável, com regras sobre o meio ambiente e condições de trabalho, segundo o professor Rabih Nasser, em reportagem ao portal UOL (2019), o primeiro desse tipo de acordo foi firmado com a Coreia do Sul, em vigor desde 2011, considerando aspectos ambientais, trabalhista e comercial de forma equilibrada priorizando o desenvolvimento sustentável.

Dessa forma, a minuta de acordo firmada entre os UE e Mercosul, segue essa premissa fundamental do desenvolvimento com responsabilidade ambiental e social. O Brasil tem especial relevância nesse contexto por possui a maior área florestada do mundo, razão pela qual, o acordo firmado entre os blocos ultrapassam os interesses meramente econômicos tratando de uma premissa para a integração civilizatória que conciliem desenvolvimento, valorização do trabalho e preservação ambiental, com um capítulo inteiramente dedicado ao tema como veremos.

\section{Metodologia de Análise}

A metodologia utilizada nesse artigo é a análise normativa de caráter qualitativo e descritivo da minuta do acordo, disponível no site do Ministério das Relações Exteriores do Governo do Brasil. Subsidiariamente aplicou-se a pesquisa bibliográfica complementar e à hermenêutica jurídica, para interpretação dos artigos do texto de lei com indicação do princípio de direito relacionado.

A publicação oficial analisada é divulgada em língua inglesa, de tal forma que, no presente artigo, foi realizada a livre tradução de trechos relevante da minuta do acordo, seguido da breve análise. Por hermenêutica jurídica adotamos nesse trabalho o conceito Maximiliano (2020) no qual a hermenêutica jurídica tem por objeto o estudo e a sistematização dos processos aplicáveis para determinar o sentido e o alcance da norma, nesse sentido aplica-se para dar entendimento interpretativo ao texto de lei (Maximiliano, 2020).

Dessa forma o objetivo não é esgotar o debate no que tange ao direito ambiental, nem propor análises definidora do texto de lei ou do alcance do acordo, mas sim, servir como uma introdução que facilite o contato de novos pesquisadores com essa nova agenda de pesquisa que emergirá das diretrizes de política ambiental estabelecidas nesse tratado.

\section{Aspectos Ambientais da minuta de Acordo União Europeia - Mercosul}

Passemos a exposição e análise do teor do acordo em seu capítulo intitulado "Comercio e Desenvolvimento Sustentável" no que tange as questões de política Ambiental.

Segundo o site oficial do Itamaraty (Brasil, 2019), o texto do acordo é divulgado á luz do crescente interesse do público, a fim de garantir tanto o efetivo exercício do direito de acesso à informação pública quanto à transparência da gestão pública. Não obstante, a minuta de acordo pode sofrer alterações adicionais em decorrência do processo de revisão legal a que estão sujeitos. Dessa forma, uma versão final do acordo só restara definitiva após a ratificação de todas as partes, ou seja, após a conclusão dos tramites legais fixados para a entrada em vigor em cada país dos dois blocos econômicos. 
O capítulo da minuta em questão que versa sobre aspectos ambientais do tratado é intitulado "Comércio e desenvolvimento sustentável (Trade and sustainable development)" e está estruturado em 18 artigos, com pactos relacionados a proteção ao meio ambiente, do trabalho e do desenvolvimento sustentável, passemos ao teor de seus artigos.

O Artigo 1 apresenta como Objetivo aumentar a integração do desenvolvimento sustentável nas relações comercial e de investimento, estabelecendo princípios e ações relativos ao trabalho e aos aspectos ambientais do desenvolvimento sustentável. As Partes se comprometem com acordo multilaterais já firmados, nomeadamente: as metas da Agenda 21 e a Declaração do Rio sobre Meio Ambiente e Desenvolvimento de 1992, a Declaração de Joanesburgo sobre Desenvolvimento Sustentável e o Plano de Joanesburgo de Implementação sobre Desenvolvimento Sustentável de 2002, a Declaração Ministerial do Conselho Econômico e Social das Nações Unidas sobre a criação de um meio ambiente em nível nacional e internacional propícios à geração de emprego pleno e produtivo e trabalho decente para todos, e seu impacto no desenvolvimento sustentável de 2006, a Declaração sobre Justiça Social para a Globalização de 2008 da Organização Internacional do Trabalho (OIT), e o Documento Final da Conferência das Nações Unidas sobre Desenvolvimento Sustentável de 2012 intitulada "O Futuro que Queremos" e a documento "Transformando nosso mundo: a Agenda 2030 para o Desenvolvimento Sustentável", adotado em 2015.

Ainda pelo teor do Artigo 1, os pactuados reconhecem que as dimensões econômica, social e ambiental são dimensões interdependentes e que se reforçam mutuamente, reafirmam o compromisso de promover o desenvolvimento do comércio internacional de forma a contribuir para os objetivos do desenvolvimento sustentável, para o bem-estar das gerações presentes e futuras. A promoção desse desenvolvimento econômico se dará por meio de: desenvolvimento de relações comerciais de uma maneira que contribua para alcançar os Objetivos de Desenvolvimento Sustentável; o respeito aos seus compromissos multilaterais nos campos do trabalho e do meio Ambiente; e reconhecimento dos diferentes níveis de desenvolvimentos dos países envolvidos, reforçando a cooperação em políticas e medidas ambientais, levando em consideração as diferentes realidades, capacidades, necessidades e níveis de desenvolvimento e o respeito às políticas nacionais.

$\mathrm{O}$ artigo 2 se refere aos Direitos de regulação e aos níveis de proteção, por seu teor os pactuantes do acordo reconhecem o direito de cada Parte de determinar seu desenvolvimento sustentável e suas políticas e prioridades, para estabelecer os níveis de proteção ambiental e trabalhista a nível local, não obstante, estabelece que essas regulações e políticas domesticas devem ser condizentes com o compromisso e os acordos internacionais já ratificados. O referido artigo estabelece também que as parte não podem enfraquecer os níveis de proteção ambiental e trabalhista doméstico, com a intenção de estimular o comércio ou investimento.

O Artigo 3 trata das regras de Transparência das medidas destinadas a proteção ambiental e do trabalho que devem garantir a conscientização e incentivando a participação do público, de acordo com suas regras e procedimentos internos.

Já o Artigo 4 Normas e acordos multilaterais de trabalho acorda a obediência dos pactuantes as regras multilaterais de trabalho, dando ênfase as regulamentações da OIT (Organização Mundial do Trabalho) com destaque para adoção de medidas que eliminem o trabalho forçado, obrigatório, escravo e infantil e valorizem a dignidade do trabalho. Um pacto por condições de trabalho decentes para todos, no que diz respeito, a salários e rendimentos, jornada de trabalho e outras condições além da saúde do trabalhador.

No Artigo 5 intitulado Acordos Ambientais Multilaterais os pactuantes reconhecem que o meio ambiente é uma das três dimensões da sustentabilidade em suas três dimensões, que seja, econômica, social e ambiental. Devem, portanto, ser abordadas de forma equilibrada e integrada. Além disso, reconhecem a contribuição que o comércio pode trazer para o desenvolvimento sustentável. O artigo trás como premissa o reconhecimento da relevância da Assembleia das Nações Unidas para o Meio Ambiente (UNEA) do Programa das Nações Unidas para o Meio Ambiente (PNUMA) e acordos ambientais multilaterais como uma resposta da comunidade internacional aos desafios ambientais globais ou regionais além da necessidade de reforçar o apoio 
mútuo entre as políticas comerciais e ambientais. Também reafirma reafirmar os compromissos de promover e implementar efetivamente, acordos ambientais multilaterais (MEAs), devendo prestar informações sobre seus respectivos progressos.

O Artigo 6 Comércio e Mudanças climáticas estabelece que os países do Mercosul e da União Europeia reconhecem a importância de buscar o objetivo final do Convenção-Quadro das Nações Unidas sobre Mudança do Clima (UNFCCC), a fim de abordar de forma urgente a ameaça das alterações climáticas e o papel do comércio para este fim. As partes devem implementar efetivamente a UNFCCC e o Acordo de Paris, promovendo políticas para baixas emissões de gases de efeito estufa e aumentar a capacidade de se adaptar aos impactos adversos das mudanças climáticas.

No artigo 7 intitulado Comércio e biodiversidade os acordantes reconhecem a importância da conservação e uso sustentável de produtos da diversidade biológica, zelado pelo cumprimentos dos acordos internacionais relacionados a Convenção sobre Diversidade Biológica (CDB), a Convenção sobre Comércio Internacional de Espécies Ameaçadas de Fauna e Flora Selvagem (CITES), o Tratado Internacional sobre Recursos Genéticos Vegetais para Alimentos e Agricultura, e as decisões adotadas nos termos do mesmo e o papel que o comércio pode desempenhar ao contribuir para os objetivos desses acordos.

Para efetividade dessas medidas o acordo estabelece que: a) Os países pactuantes devem promover a utilização da CITES como instrumento de conservação e uso sustentável da biodiversidade; b) implementar medidas eficazes que levem à redução do comércio ilegal de vida selvagem; c) incentivar o comércio de produtos baseados em recursos naturais obtidos por meio da utilização de recursos biológicos ou que contribuam para a conservação da biodiversidade; d) promover a repartição justa e equitativa dos benefícios decorrentes do uso de recursos genéticos e, quando apropriado, medidas para acesso a tais recursos.

O artigo 8 trata sobre Comércio e gestão sustentável de florestas estabelecendo que as partes reconhecem a importância do manejo florestal sustentável e o papel do comércio na persecução deste objetivo e da restauração florestal para a conservação e uso sustentável. Para o alcance desses objetivos deverá os pactuantes: a) incentivar o comércio de produtos de florestas geridas de forma sustentável; b) promover a inclusão de comunidades locais baseadas na floresta e povos indígenas em cadeias de abastecimento sustentáveis de madeira e produtos florestais não madeireiros, como um meio de melhorar seus meios de subsistência e de promovera conservação e uso sustentável das florestas; c) implementar medidas para combater a extração ilegal de madeira e o comércio relacionado;

O Artigo 9 se refere a Comércio e gestão sustentável da pesca e da aquicultura o texto prevê que as Partes reconhecem a importância de conservar e gerir de forma sustentável recursos biológicos e ecossistemas marinhos, bem como de promoção responsável e sustentável da aqüicultura, e o papel do comércio na busca desses objetivos e seu compromisso em alcançar a Meta de Desenvolvimento Sustentável 14 da Agenda 2030 para o Desenvolvimento Sustentável, particularmente as ODS 14.4 e 14. Para tais objetivos estabelece: a) implementar medidas de conservação e gestão de longo prazo e exploração dos recursos marinhos vivos de acordo com o direito internacional consagrado na Convenção das Nações Unidas sobre o Direito do Mar de 1982 e outras Nações Unidas e FAO (Organização das Nações Unidas para Alimentação e Agricultura) relevantes instrumentos de que é parte; b) agir de acordo com os princípios do Código de Conduta para Responsáveis da FAO Pesca; c) participar e cooperar ativamente com a Organizações regionais de gestão de pescas (RFMOs) e outros fóruns internacionais com o objetivo de alcançar uma boa governança e pesca sustentável; d) implementar, de acordo com seus compromissos internacionais, abrangente, eficaz e medidas transparentes para combater a pesca (IUU) e excluir do comércio internacional produtos que não cumpram tais medidas, e cooperem para esse fim; e) trabalhar com vista a coordenar as medidas necessárias à conservação e uso sustentável de estoques de peixes transzonais em áreas de interesse comum; f) promover o desenvolvimento de uma aquicultura sustentável e responsável, levando em consideração seus aspectos econômicos, sociais e ambientais, inclusive no que diz respeito à implantação dos objetivos e princípios contidos no Código de Conduta para Responsáveis da FAO Pesca. 
No artigo 10 Informação Científica e Técnica estabelece que ao implementar medidas destinadas a proteger o meio ambiente, o trabalho e demais condições que possam afetar o comércio ou o investimento, cada Parte deve assegurar que as evidências técnicas nas quais se baseiam provêm de órgãos técnicos e científicos reconhecidos e que as medidas são baseadas em normas, diretrizes ou recomendações internacionais. Nos casos em que as evidências ou informações científicas são insuficientes ou inconclusivas e há risco de grave degradação ambiental ou para a saúde e segurança ocupacional em seu território, a Parte pode adotar medidas com base no princípio da precaução. Tais medidas serão baseadas em informações pertinentes disponíveis e sujeitas a revisão periódica. Em suma, o artigo impõem o critério técnico cientifico como norteador de quaisquer políticas públicas adotadas pelos países signatários.

No que tange ao Artigo 11 intitulado Gestão comercial e responsável das cadeias de abastecimento fica pactuado que as partes reconhecem a importância da gestão responsável das cadeias de abastecimento por meio de conduta de negócios responsável e práticas de responsabilidade social corporativa baseadas orientação internacional, tais como a Declaração Tripartite de Princípios da OIT sobre Empresas Multinacionais e Política Social, o Pacto Global da ONU, o Guia da ONU Princípios sobre Empresas e Direitos Humanos e as Diretrizes da OCDE para Multinacionais Empreendimentos.

O Artigo 12, Outras iniciativas relacionadas a comércio e investimentos que favorecem o desenvolvimento sustentável estabelece que as Partes confirmam seu compromisso de aumentar a contribuição do comércio e do investimento para o objetivo do desenvolvimento sustentável em suas dimensões econômica, social e ambiental, promovendo os objetivos da Agenda de Trabalho Decente, em consonância com a OIT 2008 Declaração sobre Justiça Social para uma Globalização Justa, incluindo o salário mínimo de subsistência, proteção social inclusiva, saúde e segurança no trabalho e outros aspectos relacionados as condições de trabalho.

Artigo 13, intitulado Trabalhando juntos em comércio e desenvolvimento sustentável pactua o compromisso entre os signatários em trabalhar em conjunto nas seguintes pontos: a) aspectos trabalhistas e ambientais do comércio e desenvolvimento sustentável em fóruns internacionais, incluindo em particular a OMC, a OIT, o PNUMA, a UNCTAD, de alto nível Fórum Político para o Desenvolvimento Sustentável e acordos ambientais multilaterais(MEAs); b) leis e normas trabalhistas e ambientais no comércio e nos investimentos; c) leis de comércio e investimento no trabalho e no meio ambiente; d) esquemas voluntários de garantia de sustentabilidade, como esquemas de comércio justo e ético e rótulos ecológicos por meio da troca de experiências e informações sobre esses sistemas; e) a implementação de convenções fundamentais, prioritárias e outras convenções da OIT atualizadas; f) a Agenda de Trabalho Decente da OIT, incluindo as interligações entre comércio ee emprego produtivo, ajuste do mercado de trabalho, normas trabalhistas fundamentais, trabalho decente em cadeias de abastecimento globais, proteção social e inclusão social, diálogo social, competências desenvolvimento e igualdade de gênero; g) a implementação de MEAs e o apoio à participação mútua em tais MEAs; h) o regime de mudança climática internacional dinâmico sob a UNFCCC, em particular a implementação do Acordo de Paris; i) o Protocolo de Montreal e quaisquer emendas a ele ratificadas pelas Partes, em particular medidas para controlar a produção, o consumo e o comércio de empobrecimento do ozônio Substâncias (ODS) e Hidrofluorcarbonetos (HFCs), e a promoção do meio ambiente alternativas amigáveis para eles, e medidas para combater o comércio ilegal de substâncias regulamentadas poro protocolo; j) responsabilidade social corporativa, conduta empresarial responsável, responsável gestão das cadeias de abastecimento globais e responsabilidade, incluindo no que diz respeito a implementação, acompanhamento e disseminação de instrumentos internacionais relevantes; k) a boa gestão de produtos químicos e resíduos; 1) a conservação e uso sustentável da diversidade biológica, e a feira e repartição equitativa dos benefícios decorrentes da utilização de recursos genéticos, inclusive por acesso adequado a esses recursos; m) combate ao tráfico de vida selvagem; n) a promoção da conservação e manejo sustentável das florestas com vistas à redução do desmatamento e da extração ilegal de madeira; o) iniciativas privadas e públicas que contribuem para o objetivo de conter o desmatamento,incluindo aqueles que ligam produção e consumo por meio de cadeias de abastecimento, consistentes com a ODS 12 e 15; p) a promoção 
de práticas de pesca sustentáveis e comércio de peixes manejados de forma sustentável; q) consumo sustentável e iniciativas de produção consistentes com o ODS 12,incluindo, mas não se limitando a, economia circular e outros modelos econômicos sustentáveis destinados no aumento da eficiência dos recursos e na redução da geração de resíduos.

O Artigo 14 Artigo estabelece o Subcomitê de Comércio e Desenvolvimento Sustentável e Pontos de Contato que deve se reunir no prazo de um ano a partir da data de entrada em vigor do Acordo, tendo por objetivos o monitoramento dos pontos do acordo e a operacionalidade dos artigos 16 e 17 do mesmo.

O Artigo 15 estabelece diretrizes gerais para Resolução de disputas estabelecendo que as Partes envidarão todos os esforços por meio do diálogo, consulta e troca de informação cooperação para resolver qualquer divergência sobre a interpretação ou aplicação deste acordo. O Artigo 16, também é operacional é estabelece normas para a Consulta dos membros do acordo, as Partes entrarão em consultas com o objetivo de alcançar um acordo mutuamente satisfatório com resolução da questão. Em assuntos relacionados aos acordos multilaterais referidos as Partes devem levar em consideração as informações da OIT ou de organizações relevantes ou órgãos responsáveis pelos acordos ambientais multilaterais ratificados. Já é o Artigo 17 nomeclaturado Painel de especialistas estabelece a possibilidade de formação de um painel técnico de especialista para a solução de controvérsia e as formas e procedimentos burocráticos para a atuação desse painel.

Por fim, o Artigo 18 intitulado Revisão estabelece com a finalidade de aumentar a realização dos objetivos do acordo, a possibilidade das realizarem a revisão de suas disposições, levando em consideração, a experiência adquirida, desenvolvimentos de políticas por cada membro, utilizando como instancia para tal Subcomitê de Comércio e Sustentabilidade.

O Quadro 1 abaixo, apresenta uma síntese da análise realizada nesse capítulo, com uma breve descrição do teor de cada artigo e os principais princípios de direitos e tratados internacionais referenciados no em cada termo.

Quadro 1. Quadro síntese da análise da minuta do acordo entre UE e MERCOSU.

\begin{tabular}{|c|c|c|}
\hline \multicolumn{3}{|c|}{ Quadro síntese } \\
\hline Título do artigo & Descrição do caput do artigo & Princípios de direito e tratados relacionados. \\
\hline $\begin{array}{l}\text { Artigo } 1 \text { Objectives and Scope } \\
\text { (Objetivos e Escopo) }\end{array}$ & $\begin{array}{l}\text { As partes se comprometem a cumprir os acordos } \\
\text { internacionais já firmados: 1) Metas da Agenda } 21 \text { e a } \\
\text { Declaração do Rio sobre Meio Ambiente e } \\
\text { Desenvolvimento de 1992; 2) Declaração e Joanesburgo } \\
\text { sobre Desenvolvimento Sustentável de 2002; 3) } \\
\text { Declaração Ministerial do Conselho Econômico e Social } \\
\text { das Nações Unidas sobre a criação de um meio ambiente } \\
\text { em nível nacional e internacional propícios à geração de } \\
\text { emprego pleno 2006; 3) Declaração sobre Justiça Social } \\
\text { para a Globalização de } 2008 \text { (OIT); 4) Documento Final } \\
\text { da Conferência das Nações Unidas sobre } \\
\text { Desenvolvimento Sustentável de 2012 "O Futuro que } \\
\text { Queremos"; Documento "Transformando nosso mundo: } \\
\text { a Agenda 2030 para o Desenvolvimento Sustentável"; }\end{array}$ & $\begin{array}{l}\text { Define os objetivos do acordo; Compromisso dos estados } \\
\text { signatários de manterem e cumprirem os tratados internacionais } \\
\text { de meio ambiente e desenvolvimento sustentável; Reforça o } \\
\text { princípio do desenvolvimento sustentável afirmando as } \\
\text { dimensões ambientais, sociais e trabalhistas como integradas e } \\
\text { indissociáveis; Considera as disparidades econômicas dos países } \\
\text { e os diferentes níveis de desenvolvimento; Reforça a cooperação } \\
\text { para o desenvolvimento de políticas públicas e o respeito as } \\
\text { políticas internas de cada país. }\end{array}$ \\
\hline $\begin{array}{l}\text { Artigo } 2 \text { Right to regulate and } \\
\text { levels of protection (Direito de } \\
\text { regular e níveis de proteção) }\end{array}$ & $\begin{array}{l}\text { Os pactuantes reconhecem o direito de cada Parte de } \\
\text { determinar seu desenvolvimento sustentável e suas } \\
\text { políticas e prioridades no estabelecimento dos níveis de } \\
\text { proteção ambiental e trabalhista local, não obstante, } \\
\text { estabelece que essas regulações e políticas domesticas } \\
\text { devem ser condizentes com o compromisso e os acordos } \\
\text { internacionais já ratificados. As Parte não podem } \\
\text { enfraquecer os níveis de proteção ambiental e trabalhista } \\
\text { doméstico, com a intenção de estimular o comércio ou } \\
\text { investimento }\end{array}$ & $\begin{array}{l}\text { Trata do Direito de regulação dos países signatários e dos níveis } \\
\text { de proteção; afirma o princípio da proibição ao retrocesso social } \\
\text { e ambiental; estabelece parâmetros mínimos para a legislação } \\
\text { domestica ambiental e trabalhista com base nos acordos } \\
\text { internacionais citados no artigo 1; veda o enfraquecimento da } \\
\text { legislação nacional de proteção social, trabalhista e ambiental } \\
\text { como meio para alcançar maior competitividade comercial e de } \\
\text { investimento. }\end{array}$ \\
\hline $\begin{array}{l}\text { Artigo } \quad 3 \\
\text { (Transparência) }\end{array}$ & $\begin{array}{l}\text { Os signatários devem garantir que o desenvolvimento, a } \\
\text { promulgação e a implementação de medidas destinadas a } \\
\text { proteger o meio ambiente e as condições de trabalho que } \\
\text { possam afetar o comércio ou o investimento, ou medidas } \\
\text { de comércio ou investimento que possam afetar a } \\
\text { proteção do meio ambiente ou das condições de trabalho, } \\
\text { são realizadas de forma transparente, garantindo a } \\
\text { conscientização e incentivando a participação pública, de } \\
\text { acordo com suas normas e procedimentos nacionais. }\end{array}$ & $\begin{array}{l}\text { O artigo preconiza o princípio da transparência, nas ações } \\
\text { ambientais e sociais; afirma que as dimensões econômica, social } \\
\text { e ambiental são interdependentes e se reforçam mutuamente nas } \\
\text { dimensões do desenvolvimento sustentável; reforça a soberania } \\
\text { das legislações doméstica e a participação do Estado; Contudo, } \\
\text { não apresenta nem sugestiona meios para a promoção efetiva da } \\
\text { transparência na execução das políticas públicas. }\end{array}$ \\
\hline
\end{tabular}




\begin{tabular}{|c|c|c|}
\hline $\begin{array}{l}\text { Artigo } 4 \text { Multilateral } \text { Labour } \\
\text { Standards and Agreements } \\
\text { (Normas e acordos multilaterais de } \\
\text { trabalho) }\end{array}$ & $\begin{array}{l}\text { Os pactuantes se comprometem com a obediência dos } \\
\text { acordos multilaterais de trabalho e as regulamentações da } \\
\text { OIT (Organização Mundial do Trabalho) com destaque } \\
\text { para adoção de medidas que eliminem o trabalho forçado, } \\
\text { obrigatório, escravo e infantil e valorizem a dignidade do } \\
\text { trabalho, garantido condições de trabalho decentes para } \\
\text { todos, no que diz respeito, a salários e rendimentos, } \\
\text { jornada de trabalho e outras condições além da saúde do } \\
\text { trabalhador. }\end{array}$ & $\begin{array}{l}\text { Reitera o princípio da dignidade da pessoa humana, o princípio } \\
\text { da vedação ao retrocesso social e os princípios gerais de direito } \\
\text { do trabalho já presente na legislação brasileira; Os signatários } \\
\text { devem manter as normas trabalhistas segundo as diretrizes da } \\
\text { OIT; O artigo é extenso e estabelece metas tal como: 1) Promover } \\
\text { a plena liberdade de associação e o reconhecimento efetivo do } \\
\text { direito à negociação coletiva, favorecendo os princípios sindicai } \\
\text { e cooperativos; 2) A eliminação de todas as formas de trabalho } \\
\text { forçado ou obrigatório; 3) A abolição efetiva do trabalho infantil; } \\
\text { e a eliminação da discriminação no emprego e na ocupação. }\end{array}$ \\
\hline $\begin{array}{lr}\text { Artigo } 5 & \text { Multilateral } \\
\text { Environmental } & \text { Agreements } \\
\text { (Acordos } & \text { Ambientais } \\
\text { Multilaterais) } & \end{array}$ & $\begin{array}{l}\text { Os signatários reconhecem que o meio ambiente é uma } \\
\text { das três dimensões do desenvolvimento sustentável - } \\
\text { econômica, social e ambiental - devem ser tratadas de } \\
\text { forma equilibrada e integrada. Comprometem-se com a } \\
\text { Assembleia das Nações Unidas para o Meio Ambiente } \\
\text { (UNEA) do Programa das Nações Unidas para o Meio } \\
\text { Ambiente (PNUMA) e dos acordos multilaterais sobre } \\
\text { meio ambiente como uma resposta da comunidade } \\
\text { internacional aos desafios ambientais globais. Cada parte } \\
\text { reafirma seus compromissos de promover e implementar } \\
\text { efetivamente os acordos ambientais multilaterais } \\
\text { (MEAs), os protocolos e suas emendas dos quais seja } \\
\text { parte. }\end{array}$ & $\begin{array}{l}\text { O artigo enfatiza o multilateralismo como caminho para o } \\
\text { desenvolvimento reafirmando os tratados internacionais firmados } \\
\text { em com acordos multilaterais e com as instancia da ONU (UNEA, } \\
\text { PNUMA). Reafirma o desenvolvimento enquanto política } \\
\text { integrada e indissociável de seus aspectos ambientais, } \\
\text { econômicos e sociais. }\end{array}$ \\
\hline $\begin{array}{l}\text { Artigo } 6 \text { Trade and Climate Change } \\
\text { (Comércio e mudanças climáticas) }\end{array}$ & $\begin{array}{l}\text { Os signatários se comprometem a abordar a ameaça } \\
\text { urgente da mudança do clima e o papel do comércio para } \\
\text { esse fim. Devem também cooperar, conforme apropriado, } \\
\text { em questões de mudanças climáticas relacionadas com o } \\
\text { comércio a nível bilateral, regional e em nos fóruns } \\
\text { internacionais. }\end{array}$ & $\begin{array}{l}\text { Reafirma o princí́io da irretroatividade das leis ambientais que } \\
\text { condiciona os países signatário ao cumprimento das metas do } \\
\text { acordo de Paris e da Convenção-Quadro das Nações Unidas sobre } \\
\text { Mudança do Clima. }\end{array}$ \\
\hline $\begin{array}{l}\text { Artigo } 7 \text { Trade and Biodiversity } \\
\text { (Comércio e biodiversidade) }\end{array}$ & $\begin{array}{l}\text { Os signatários reconhecem a importância da conservação } \\
\text { e do uso sustentável da diversidade biológica. Se } \\
\text { comprometem a trocar informações sobre iniciativas e } \\
\text { boas práticas no comércio de produtos baseados em } \\
\text { recursos naturais com o objetivo de conservar a } \\
\text { diversidade biológica em cooperação. }\end{array}$ & $\begin{array}{l}\text { Reafirma os compromissos da Convenção sobre Diversidade } \\
\text { Biológica (CDB), da Convenção sobre Comércio Internacional de } \\
\text { Espécies Ameaçadas de Fauna e Flora Selvagem (CITES), e o } \\
\text { Tratado Internacional sobre Recursos Genéticos Vegetais para } \\
\text { Alimentos e Agricultura. }\end{array}$ \\
\hline $\begin{array}{l}\text { Artigo } 8 \text { Trade and Sustainable } \\
\text { Management of Forests (Comércio } \\
\text { e gestão sustentável de florestas) }\end{array}$ & $\begin{array}{l}\text { Os signatários reconhecem a importância da gestão } \\
\text { florestal sustentável e o papel do comércio na } \\
\text { prossecução deste objetivo e da restauração florestal para } \\
\text { conservação e uso sustentável. }\end{array}$ & $\begin{array}{l}\text { Reafirma o compromisso relativos ao comércio e à conservação } \\
\text { da cobertura florestal, bem como ao manejo florestal sustentável, } \\
\text { de acordo com a Agenda } 2030 \text { para o Desenvolvimento } \\
\text { Sustentável, em especial o compromisso } 15 \text {. }\end{array}$ \\
\hline $\begin{array}{l}\text { Artigo } 9 \text { Trade and Sustainable } \\
\text { Management of } \begin{array}{llr}\text { Fisheries and } \\
\text { Aquaculture (Comércio e gestão } \\
\text { sustentável da pesca e } & \text { da } \\
\text { aquicultura) }\end{array}\end{array}$ & $\begin{array}{l}\text { Os signatários reconhecem a importância de conservar e } \\
\text { gerir de forma sustentável os recursos biológicos } \\
\text { marinhos e os ecossistemas marinhos, bem como de } \\
\text { promover a aquicultura responsável e sustentável, e o } \\
\text { papel do comércio na prossecução destes objetivos. }\end{array}$ & $\begin{array}{l}\text { Reafirma o compromisso } 14 \text { Objetivo de Desenvolvimento } \\
\text { Sustentável particularmente os itens } 14.4 \text { e } 14.6 \text {. }\end{array}$ \\
\hline $\begin{array}{l}\text { Artigo } 10 \text { Scientific and Technical } \\
\text { Information (Informação Científica } \\
\text { e Técnica) }\end{array}$ & $\begin{array}{l}\text { Ao estabelecer medidas destinadas a proteger o meio } \\
\text { ambiente ou as condições de trabalho que possam afetar } \\
\text { o comércio ou o investimento, as partes deve assegurar } \\
\text { que as evidências científicase etécnicas em que se baseiam } \\
\text { provêm de órgãos reconhecidos e que as medidas se } \\
\text { baseiam em normas, diretrizes ou recomendações } \\
\text { internacionais, quando existentes. Nos casos em que as } \\
\text { evidências ou informações científicas forem insuficientes } \\
\text { ou inconclusivas e houver risco de grave degradação } \\
\text { ambiental ou para a saúde e segurança ocupacional em } \\
\text { seu território, deve-se adotar medidas baseadas no } \\
\text { princípio da precaução. }\end{array}$ & $\begin{array}{l}\text { Reafirma o princípio da precaução sobre eventuais atividades } \\
\text { danosas ao meio ambiente; reitera a importância das instituições, } \\
\text { técnicas para a produção e compartilhamento da produção } \\
\text { cientifica. Incentiva a cooperação cientifica. }\end{array}$ \\
\hline $\begin{array}{l}\text { Artigo } 11 \text { Trade and Responsible } \\
\text { Management of Supply Chains } \\
\text { (Gestão comercial e responsável } \\
\text { das cadeias de abastecimento) }\end{array}$ & $\begin{array}{l}\text { As Partes reconhecem a importância da gestão } \\
\text { responsável das cadeias de abastecimento por meio de } \\
\text { uma conduta comercial responsável e práticas de } \\
\text { responsabilidade social corporativa com base em } \\
\text { orientações acordadas internacionalmente. }\end{array}$ & $\begin{array}{l}\text { Reafirma o compromisso relativos ao uso de instrumentos } \\
\text { internacionais tais como a Declaração Tripartida de Princípios da } \\
\text { OIT sobre Empresas Multinacionais e Política Social, o Pacto } \\
\text { Global da ONU, os Princípios Orientadores das Nações Unidas } \\
\text { sobre Negócios e Direitos Humanos e as Diretrizes da OCDE para } \\
\text { Empresas multinacionais }\end{array}$ \\
\hline
\end{tabular}


Artigo 12 Other Trade and Investment-related Initiatives Favouring Sustainable Development (Outras iniciativas relacionadas a comércio e investimentos que favorecem o desenvolvimento sustentável)
As Partes confirmam seu compromisso de aumentar a contribuição do comércio e do investimento para o objetivo do desenvolvimento sustentável em suas dimensões econômica, social e ambiental.
Reafirma o compromisso com a declaração da OIT de 2008 sobre Justiça Social para uma Globalização Justa, incluindo o salário mínimo vital, proteção social inclusiva, saúde e segurança no trabalho e outros aspectos relacionados às condições de trabalho;

Trabalho cooperativo entre os países signatários com destaque para: aspectos trabalhistas e ambientais do comércio e do desenvolvimento sustentável em fóruns internacionais, incluindo, em particular, a OMC, a OIT, o PNUMA, a UNCTAD; a Agenda de Trabalho Decente da OIT, incluindo as interligações entre comércio e emprego pleno e produtivo, ajuste do mercado de trabalho, normas trabalhistas fundamentais, trabalho decente nas cadeias de abastecimento globais, proteção social e inclusão social, diálogo social, desenvolvimento de habilidades e igualdade de gênero; mudanças climáticas no âmbito da UNFCCC, em particular a implementação do Acordo de Paris; o Protocolo de Montreal e quaisquer emendas a ele ratificadas pelas Partes, em particular medidas para controlar a produção, o consumo e o comércio de Substâncias que Destroem o Ozônio (SDO) e Hidrofluorcarbonetos (HFCs); iniciativas privadas e públicas que contribuem para o objetivo de conter o desmatamento, incluindo aquelas que vinculam a produção e o consumo por meio de cadeias de abastecimento, de acordo com os ODS 12 e 15; dentre outros.

Artigo 14 Sub-Committee on Trade and Sustainable Development and Contact Points (Subcomitê de Comércio e Desenvolvimento Sustentável e Pontos de Contato)

As partes signatárias estabelecem um Subcomitê de Comércio e Desenvolvimento Sustentável (denominado "Subcomitê de TSD").

As partes signatárias envidarão todos os esforços, por meio do diálogo, consulta, troca de informações e cooperação, para resolver qualquer desacordo sobre a interpretação ou aplicação deste Capítulo.

Artigo 15 Dispute Resolution (Resolução de disputas)

Artigo $16 \quad$ Consultations
(Consultas)

As partes podem solicitar consultas com outras partes, sobre a interpretação, aplicação e cumprimento das metas do presente Capítulo.

Estabelece a possibilidade de as partes convocar um painel de especialistas, se, dentro de 120 dias a partir da solicitação de consultas nos termos do Artigo 16, nenhuma resolução mutuamente satisfatória for alcançada.

Artigo 17 Panel of Experts (Paine de especialistas)

Com a finalidade de melhorar a realização dos objetivos deste Capítulo, as Partes, por meio das reuniões do Subcomitê de Comércio e Desenvolvimento Sustentável devem verificar a implementação efetiva das metas, incluindo uma possível revisão de suas disposições.
Objetiva monitorar a implementação efetiva deste Capítulo, incluindo atividades de cooperação.

Estabelece diretrizes gerais para Resolução de disputas.

Reitera o princípio da transparência entre os países signatário; pressupõem a possibilidade de fiscalização multa entre as partes.

O painel de especialista será vinculado ao Subcomitê TSD será composto por 15 indivíduos. A lista será composta por três sublistas: uma sublista proposta pela UE, uma sublista proposta pelo MERCOSUL e uma sublista de pessoas que não são

Reafirma todos os princípios anteriores prevendo a possibilidade de revisão das metas até então estabelecidas, desde que haja fundamentação técnico cientifica; Afirma o princípio da mediação internacional como meio para revisão de metas através do Subcomitê de Comércio e Desenvolvimento Sustentável. nacionais de nenhuma das Partes.

Fonte: Autores.

Da análise do capítulo em comento, sintetizada no quadro, pode-se notar uma preocupação do legislador proponente em reafirmar diversos tratados internacionais no campo da proteção da natureza, mudanças climáticas, proteção da biodiversidade e gestão sustentável de recurso naturais bem como a proteção dos direitos dos trabalhadores e de práticas socioeconômica em harmonia com direitos humanos e garantias sociais. Nesse sentido, a minuta condicionando a promulgação do acordo comercial ao cumprimento de diversas metas ambientais e trabalhistas já pactuadas a nível internacionais pelos países signatários dos dois blocos econômicos.

Também é notório a menção em norma, de diversos princípios de direito tais como o princípio da dignidade da pessoa humana, princípio da irretroatividade das leis socioambientais, o princípio da precaução dentre outros já citados o que demostra, o ímpeto do acordo em condicionar a intepretação do texto de lei sobre essas bases. Por fim, também é notório que o capítulo busca colocar a proteção da natureza, do trabalho e do homem em um mesmo patamar e de forma integrada, condicionando os países signatários a buscar o desenvolvimento sustentável e que harmonize as dimensões social, econômica e ambiental. 


\section{Conclusão}

O Acordo entre Mercosul e UE é um importante instrumento para o avanço da integração intercontinental e para o desenvolvimento econômico, mais também para avanços sociais, trabalhista e principalmente de preservação do Meio Ambiente, ao consideraras três dimensões da sustentabilidade, quer seja, a econômica, social e ambiental em seu corpo de lei.

O desenvolvimento sustentável é um dos pilares dos acordos comerciais, pois é impossível promover a produção de bens e serviços em um contexto de degradação ambiental, os motivos da pressão internacional devem ser observados e o único objetivo é proteger o meio ambiente (Araujo \& Abbade, 2021)

A dinâmica do meio ambiente e comércio não é nova dentro do Mercosul, ainda no ano de 2002, foi aprovada a criação das "Pautas Negociadoras do Subgrupo de Trabalho 6 (SGT-6), uma instância composta por especialistas dos países do Mercosul em meio ambiente. As pautas compreendia principalmente medidas não tarifarias para o meio ambiente vinculas a temáticas setoriais do Acordo Quadro de Meio Ambiente, da implantação do Sistema de Informação Ambiental do Mercosul (SIAM), contudo, não se identifica uma política ambiental única, como um marco legal comum entre os países do bloco (Oliveira \& Espíndola, 2015)

Nesse sentido o acordo em questão trás significativos avanços, como visto ao longo desse artigo, o capítulo que aborda o comércio e o desenvolvimento sustentável estabeleceu diversas medidas para o fortalecimento dos níveis de proteção ambiental dos países signatários, através da afirmação de princípios fundamentais, tais com o princípio da vedação ao retrocesso social, que impende a revogação leis ambientais e trabalhistas por parte dos países. Isso significa que os países participantes do Acordo Mercosul-UE são proibidos de aumentar sua competitividade em detrimento do meio ambiente ou as custas da supressão de direitos sociais (Salgado \& Bressan, 2020).

Como vimos, a existência de um capítulo especifico sobre desenvolvimento sustentável em um acordo comercial com a União Europeia consolida uma tendencia para o fortalecimento de medidas de proteção a natureza, considerando que uma acordo com princípios similares foi estabelecido com a Coreia do Sul e está em vigor desde 2011 (Salgado \& Bressan, 2020)..

As referências a compromissos multilaterais já assumidos pelas partes na área de meio ambiente também é presente em acordos anteriores assinados pela EU. Por conseguinte, pode-se inferir que, o objetivo é garantir o comprometimento com as obrigações e as normativas assumidas pelas partes no âmbito multilateral. Para além, a UE tem adotado a prática de elencar quais são os pontos mais relevantes nas suas relações comerciais com as contrapartes, como se verifica do acordo UE-Coreia (2010) que nominou pontualmente as negociações sobre as questões climáticas com referência explícita ao Acordo-Quadro em Mudanças Climáticas, ao Protocolo de Kyoto, observa-se o incremento da complexidade desta referência nos acordos posteriores com UE-Peru-Colômbia (2011) (Badin \& Azevedo, 2013).

Padrão similar pode é observado na minuta do acordo entre EU e Mercosul em comento, no Quadro 2 abaixo, são elencados os tratados internacionais citados no capítulo "Comércio e desenvolvimento sustentável (Trade and sustainable development)", vejamos: 
Quadro 2. Tratados e convenções internacionais condicionadas ao acordo UE x MERCOSUL.

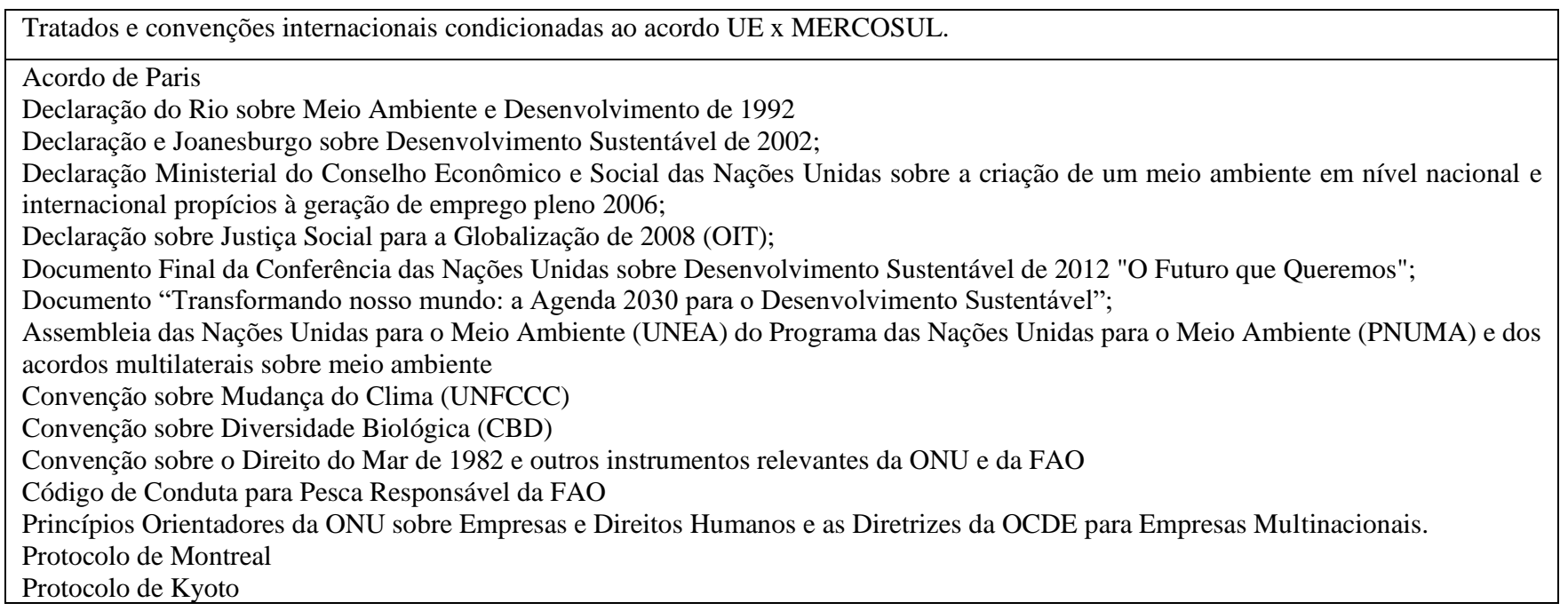

Fonte: Autores.

O acordo fortalece diversos tratados internacionais com destaque para obrigatoriedade da implementação das metas do Acordo de Paris, dos Objetivos do Desenvolvimento Sustentável. Além disso, os países signatários reconhecem a importância de manter e desenvolver florestas de forma sustentável e devem tomar medidas eficazes para combater o desmatamento e o comércio ilegal e tomar medidas para proteção da biodiversidade.

Os países também reconhecem a relevância da manutenção e da exploração sustentável de florestas, devendo aplicar medidas efetivas para o combate ao desmatamento ilegal. Entretanto, a ocorrência de elevado número de queimadas na Amazônia Brasileira, fez países da União Europeia, como França e Áustria, se posicionarem contra a ratificação do Acordo Mercosul—EU (Globo, 2021), considerando a não aplicação, por parte do Brasil, de medidas efetivas contra o desmatamento e para preservação de seus biomas.

No mais, a ratificação desse acordo depende da aprovação pelo parlamento de todos os países-membros, com o aumento do desmatamento no centro das críticas ao Brasil são necessários avanços efetivos no combate a crimes ambientais que demonstrem a disposição do governo brasileiro no efetivo cumprimento das metas pactuadas a nível internacional principalmente no que tange ao fortalecimento das políticas ambientais. É preciso recorda que, ainda em 2019, foi formalizado no âmbito europeu o pacto European Green New Deal que consiste em tornar a UE mais sustentável, reduzir as emissões de gases com efeito de estufa e investir em novas tecnologias, com vista a tornar a Europa o primeiro continente com impacto climático neutro. Uma das diretrizes desse plano é justamente construir uma "diplomacia ecológica" nos acordos assinados pelo bloco, com vistas a incluir os princípios ambientais no cerne das relações comerciais. Este pano de fundo aumenta a tensão entre a UE e o atual governo Bolsonaro, devido a sua agenda anti-ambiental notabilizada pela piora dos índices relacionados a políticas de proteção a natureza, especialmente ao desmatamento. Além disso, esse cenário atual brasileiro gera pressões dos movimentos ambientais da sociedade civil que por sua vez tem o potencial de pressionar internamente os parlamentos nacionais, colocando em risco a ratificação do o acordo entre UE-Mercosul.

Por fim, a exposição aqui realizada apenas inicia um debate que compõem uma nova agenda para os estudos de relações internacional, direito e meio ambiente, que deverá criar mecanismos metodológicos para avaliar o cumprimento das metas proposta pelo acordo entre os blocos econômicos. Pesquisas, por exemplo, que apresentem em seu escopo a análise de temas ligadas as 18 áreas dos ODS, tais com as que mensuram indicadores para boa governança, áreas protegidas, mudanças climáticas etc, terão ainda maior relevância com o advento desse acordo comercial, uma vez que, esse instrumento reafirma, esses objetivos em todas as suas dimensões. Enfim, o desenvolvimento sustentável se consolida como fundamental não só nas relações 
comerciais internacionais, mas, por conseguinte no âmbito interno de um país, uma vez que tal conceito, quando empregado por políticas públicas responsáveis, assegura a prosperidade socioambiental e econômica, respeitando os limites existentes para preservação do planeta.

\section{Referências}

Araújo, J. N. \& Abbade, K. M. (2021) A Efetividade do Acordo de Paris Frente ao Acordo de Livre-Comércio do Mercosul e União Europeia. Revista do Centro de Excelência Jean Monnet da FGV Direito Rio. 10(11). 25-38.

Badin, M. R. S. \& Azevedo, M. F. (2013) Estratégias da União Europeia em meio ambiente nos acordos regionais ee comércio e seus impactos para as negociações com o Mercosul. Boletim de Economia e Política Internacional, BEPI, n. 15. 22-29.

BBC. (2019) Mercosul e UE fecham acordo histórico. Website BBC News. https://www.bbc.com/portuguese/brasil-48808095

BRASIL. (2019) Ministério das Relações Exteriores. Conclusão das Negociações do Acordo entre o MERCOSUL e a União Europeia - Nota Conjunta dos Ministérios das Relações Exteriores, da Economia e da Agricultura, Pecuária e Abastecimento. http://www.itamaraty.gov.br/pt-BR/notas-a-imprensa/20560conclusao-das- negociacoes-do-acordo-entre-o-mercosul-e-a-uniao-europeia-nota-conjunta-dos- ministerios-das-relacoes-exteriores-da-economia-e-daagricultura-pecuaria-e- abastecimento-bruxelas-27-e-28-de-junho-de-2019

Brasil (2019) Trade And Sustainable Development: Chapter twenty EU Mercosur Association Agreement 115 http://www.itamaraty.gov.br/images/2019/Comrcio_e_Desenvolvimento_Sustenty

Brasil. (1992) A Conferência das Nações Unidas sobre meio ambiente e desenvolvimento: Declaração do Rio de Janeiro, Rio de Janeiro 1992. https://www.scielo.br/j/ea/a/szzGBPjxPqnTsHsnMSxFWPL/?lang=pt

Globo. (2021) Áustria se une a França e ameaça bloquear acordo EU por questões ambientais. https://oglobo.globo.com/economia/austria-se-une-francaameaca-bloquear-acordo-ue-mercosul-por-questoes-ambientais-24921828

Inesc. (2020) Dando nomes aos Bois: Análise das medidas infralegais para o meio ambiente nos primeiros dois anos do governo Bolsonaro. https://www.inesc.org.br/dando-nome-aos-bois-análise-das-medidas-infralegais-para-o-meio-ambiente-nos-primeiros-dois-anos-do-governo-bolsonaro/

Mapbiomas. (2021) País perdeu 24 arvores por segundo em 2020. https://mapbiomas.org/pais-perdeu-24-arvores-por-segundo-em-2020

Machado, I. \& Lupi A. (2020) O Acordo Entre Mercosul E União Europeia. Percurso, 2(33), 98-120.

Maximiliano, C. (2020) Hermenêutica e Aplicação do Direito. Ed. Forense.

Moura, A. (2020) O impacto do Acordo Mercosul-União Europeia para o Brasil. Consultor Jurídico. https://www.conjur.com.br/2019- jul-03/aline-mouraimpacto-acordo-mercosul-ue-brasil

Oliveira, C. M. \& Espíndola, I. B. (2015) Harmonização das normas jurídicas ambientais nos países do MERCOSUL. Ambiente e Sociedade, v. XVIII, n4, p.118

Pereira, L. B. V. (2019) Primeiras reflexões sobre o Acordo Mercosul-União Europeia. Conjuntura Econômica, 48-49

Rei, F. C. F. et al. (2017) Acordo De Paris: Reflexões e Desafios Para O Regime Internacional De Mudanças Climáticas. Veredas do Direito, 14(29). 81-99

Romeiro, A. R. (2012) Desenvolvimento sustentável: uma perspectiva econômico-ecológica. Revista Estudos Avançados. 26 (74), 65-91.

Salgado, V. T. \& Bressan, R. N. (2020) O acordo de associação mercosul-união europeia e a política externa brasileira. Revista Neiba, Cadernos ArgentinaBrasil, 9, 1-22

Thorstensen, V. \& Nogueira, T. (2020). O Brasil entre União Europeia e Estados Unidos: uma leitura comparada das regulações da OMC e textos do MercosulUE e USCMA. CCGI-EESP/FGV.

UOL (2019) O Que O Acordo Comercial UE-Mercosul Diz Sobre Meio Ambiente. https://economia.uol.com.br/noticias/redacao/2019/09/03/o-que-o-acordocomercial-ue-mercosul-diz-sobre-meio-ambiente.htm 